\title{
31 SUCCESSFUL DEVELOPMENT, IMPLEMENTATION, AND EVALUATION OF INFORMATION SYSTEMS: DOES HEALTHCARE SERVE AS A MODEL FOR NETWORKED ORGANIZATIONS?
}

\author{
Jos Aarts \\ Erasmus University Rotterdam \\ The Netherlands
}

Els Goorman

Erasmus University Rotterdam

The Netherlands

\section{Heather Heathfield Manchester Metropolitan University United Kingdom}

Bonnie Kaplan Center for Medical Informatics

Yale University

U.S.A.

The use of information systems in healthcare lags behind other business sectors. One of the possible reasons is that healthcare traditionally has been a "networked" organization with no "central command." The introduction and use of IS has been shaped by the different powerful actors determining the delivery of care: professional groups (such as 
physicians, pharmacists, and, to a lesser extent, nurses), healthcare organizations, insurance companies (private and/or public) and regulating bodies (including governments). Each of the actors has different knowledge reference frameworks and knowledge that seems difficult to integrate. Private businesses are more rooted in the concept of "single line of command" and are moving swiftly into networked knowledge based organizations to meet the demands of a dynamic marketplace. What has happened in healthcare suggests that the development and implementation of IS will become increasingly difficult as businesses move toward networked organizations. The four panelists are researching IS in healthcare from different theoretical angles. They propose that healthcare as an example of a networked organization bears important lessons for the IS field.

Jos Aarts is researching the design and implementation process of a large hospital information system. A major feature of the system is the order entry functionality, which allows physicians to generate orders (such as lab, radiology, and medication), schedule patient appointments for these orders, and get results. The university hospital in the study bears the characteristics of a networked organization. Medical activities are grouped in clusters (internal medicine, surgery, pediatrics, neurology, clinical psychiatry, etc.) and support groups, such as radiology and pathology, which are actually independent entities, that are continuously negotiating about patients, services, and utilization of resources. Actor-network theory provides a theoretical framework to study information systems in networked organizations (Walsham 1997). Jos will argue that the order entry functionality of the system is inscribed by a development team representing the interests of the top level management in the hospital and this inscription causes problems for physicians to accept the system (Akrich 1992). The necessary translation of the system into medical work, therefore, is problematic and a stable network of aligned interests is not yet developing.

Els Goorman studies the connection between health care providers and information and communication technology (ICT) devices in care processes. She argues that the way synergy occurs and relevant factors influencing this synergy can give understanding in the way ICT supports health care providers in their activities (Luff and Heath 1993). Studying this possible synergy between care providers and ICT can give recommendations for future development of ICT applications and how to promote this synergy. Furthermore, she is studying the (un)expected consequences of the use of these ICT devices for the work of care providers and the transparency of the care process. Data gathered by means of participatory observations and interviews will be presented.

Heather Heathfield has evaluated the use of electronic patient records in UK hospitals. The rate of success of using the electronic patient record depends very much on the arrangements made between different "networks" in a hospital, including physicians, ICT-staff, and hospital boards. In order to make sense of the evaluation results, the complex social and organizational issues that surround the use of IS need to be understood. She argues that a useful way of analyzing evaluation results is to use models from the evaluation of social programs that differentiate between the "mechanism" of an IS and the context in which it is used (Pawson and Tilley 1997). This helps to identify what "works" for "whom" in different circumstances.

Bonnie Kaplan has been actively involved in both medical informatics and in Information Systems over a long period. She will argue that understanding healthcare organizations as networked does not provide predictors for newly networking 
organizations because healthcare organizations have a different organizational structure, history, and professional legacy from business organizations. Based on research evaluating both clinical and consumer reactions to information technologies, she will describe other ways in which what has been learned in healthcare settings is applicable to other organizations. In particular, she will draw on a social interactionist theoretical framework to present both methodological approaches and empirical findings that illuminate more general concerns in IS (Anderson and Aydin 1994; Kaplan 1997).

\section{References}

Akrich, M. "The De-scription of Technical Objects," in Shaping Technology/Building Society: Studies in Sociotechnical Change, W. E. Bijker and J. Law (eds.). Cambridge, MA: The MIT Press, 1992, pp. 205-224.

Anderson, J. G., and Aydin, C. E. "Overview: Theoretical Perspectives and Methodologies for the Evaluation of Health Care Information Systems," in Evaluating Health Care Information Systems: Approaches and Applications, J. G. Anderson, C. E. Aydin and S. J. Jay (eds.). Thousand Oaks, CA: Sage, 1994, pp. 5-29.

Kaplan, B. "Addressing Organizational Issues into the Evaluation of Medical Systems," Journal of the American Medical Informatics Association (4:2), 1997, pp. 94-101.

Luff, P., and Heath, C. "System Use and Social Organization: Observations on Human-computer Interaction in an Architectural Practice," in Technology in Working Order: Studies of Work, Interaction and Technology, G. Button and H. Harper (eds.). London: Routledge, 1993.

Pawson, R., and Tilley, N. Realistic Evaluation. Thousand Oaks, CA: Sage, 1997.

Walsham, G. "Actor-network Theory and IS Research: Current Status and Future Prospects," in Information Systems and Qualitative Research, A. S. Lee, J. Liebenau and J. I. DeGross (eds.). London: Chapman \& Hall, 1997, pp. 466-480.

\section{About the Panelists}

Jos Aarts is an assistant professor of information management in healthcare at the Department of Health Policy and Management of Erasmus University Rotterdam in the Netherlands. He has a background in physics and is currently pursuing a Ph.D. on successful design and implementation of information systems in healthcare. He has published several articles about a model to teach and study the organizational impact of health informatics. He is course director of the information management program at the department and coordinates the Erasmus part in the joint University of Surrey, University of Manchester and Erasmus University Rotterdam MSc Health Informatics course. He is chairman of European Federation for Medical Informatics WG9 "Human and Organizational Issues of Medical Informatics." Jos can be reached by e-mail at j.aarts@bmg.eur.nl.

Els Goorman is a Ph.D. student at the Department of Health Policy and Management of Erasmus University Rotterdam. The title of her research is "Synergy and Transition: Information and Communication Technology, Healthcare Providers and the Primary Care Process." She teaches qualitative research methods. She is a registered nurse and has a MSc in Health Sciences from Maastricht University. Her dissertation 
dealt with a sociological perspective on the use of clinical information systems. Els can be reached by e-mail at goorman@bmg.eur.nl.

Heather Heathfield is a senior lecturer in the Department of Computer Science and Mathematics of Manchester Metropolitan University in the UK. She holds a Ph.D. from the University of Brighton in computer science on decision support systems in healthcare. Currently she is involved in the evaluation of decision support systems for general practitioners and alerting systems for chronic diseases. She was part of a multidisciplinary research team conducting an NHS commissioned evaluation of electronic patient records in use. Heather can be reached by e-mail at h.heathfield@doc.mmu.ac.uk.

Bonnie Kaplan is a lecturer at the Yale School of Medicine's Center for Medical Informatics, a Senior Scientist at Boston University's Medical Information Systems Unit, and President of Kaplan Associates. A recognized expert in evaluating organizational and user acceptance issues pertaining to clinical applications of computer information systems in medicine and health care, she is the author of over 30 refereed papers as well as numerous other articles and publications. She is on the Informatics Advisory Board for a major health care company, serves as Chair of the American Medical Informatics Association People and Organizational Issues Working Group, and is Chair of the International Medical Informatics Association WG13 “Organizational Impact of Medical Informatics" as well as editor of their newsletter. She has taught a variety of information systems courses in business administration and hospital administration programs at several universities. Her Ph.D. is from the University of Chicago. Bonnie can be reached by e-mail at bonnie.kaplan@yale.edu. 